\title{
2 Conceptual pathways to HIV risk in Eastern and Southern Africa
}

\author{
An integrative perspective on \\ the development of young \\ people in contexts of social- \\ structural vulnerability
}

\author{
Richard G. Cowden, Leigh A. Tucker and \\ Kaymarlin Govender
}

\section{Introduction}

The transition from childhood to adulthood is characterised by substantive biological, psychological, and social changes. A majority of these changes are captured under the umbrella concept of adolescence, a period in which young people undergo biological changes and fulfil key developmental tasks towards independence and self-reliance (Blakemore \& Mills, 2014; Linders, 2017). Although legal designations of adulthood (e.g. 18 years of age or older) suggest that fulfilment of this developmental process depends on shared chronological markers, there is extensive interindividual variability in the timing, tempo, and extent to which young people experience developmental changes as they transition from childhood to adulthood. In this chapter, we position adolescence within the broader ambit of the developmental continuum by referring to individuals between 10 and 24 years of age as young people. ${ }^{1}$

Compared to their counterparts in more developed parts of the world, young people in Eastern and Southern Africa (ESA) must navigate developmental milestones within environments that often pose significant short-and long-term mental and physical health risks. Understanding developmental changes that accompany the transition to adulthood is key to identifying the challenges that young people experience within the broader sociocultural context in which they live. This chapter provides an overview of theoretical positions that are central to holistically understanding the biopsychosocial development of young people. It also offers a backdrop to subsequent chapters in this book, which focus on delineating mechanisms or processes that may deter health risk behaviours and promote well-being among young people. Drawing on theoretical perspectives rooted in biology, psychology, and 


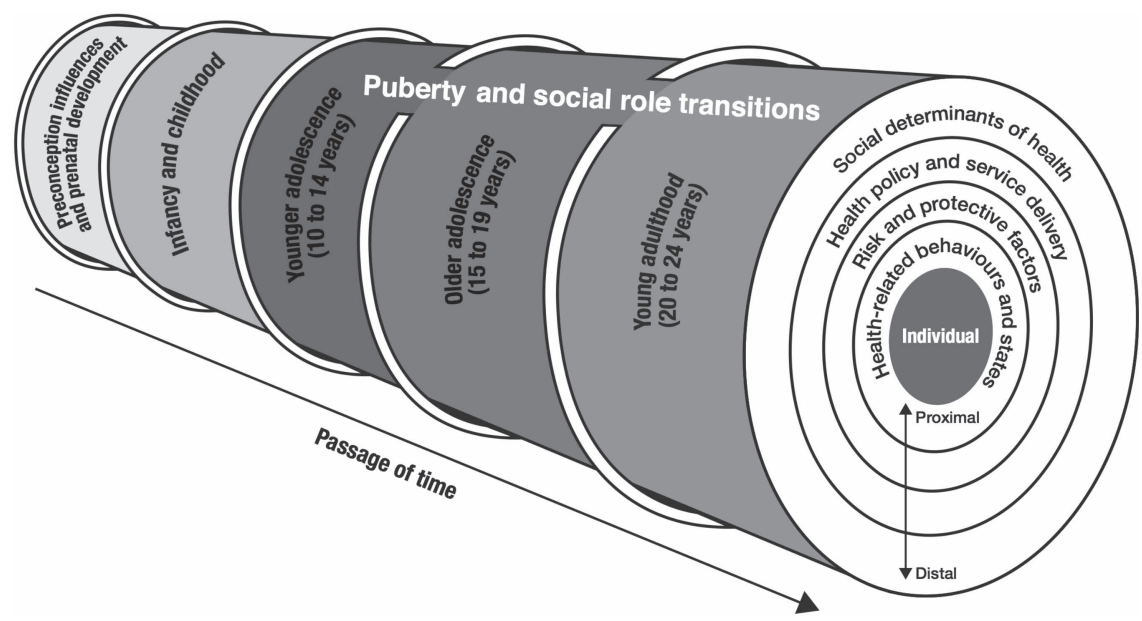

Figure 2.1 Conceptual framework for contextualised development of adolescents and young people

sociology, we outline fundamental processes that independently and conjunctively contribute to the contextualised development of young people (see Figure 2.1 for an overview of the interactive biopsychosocial systems involved in shaping the development of young people). Because HIV continues to have disproportionately devastating effects on young people living in ESA (see UNAIDS, 2017a, 2017b), understanding pathways of risk that have the potential to undermine the health and well-being of young people is integral to guiding the design and implementation of HIV prevention programming for this population.

\section{A life-course perspective on the development of young people}

Developmental psychology has traditionally dominated the way in which the experiences of young people have been constructed and understood (Burman, 2008). Traditional developmental discourse tends to assume that healthy and adaptive development is achieved through successful completion of developmental stages and attainment of age-related competencies (Burman, 2008; Hogan, 2005). This narrow perspective features several contentious assumptions, including framing development as a relatively homogenous and universal experience that is progressive, linear, and unidirectional. Emerging evidence suggests that developmental differences among young people are at least partly attributable to distinctions in both the inter- and intraindividual courses of progression, the sociocultural norms and expectations of adolescence, and the environmental context in which development occurs (Foulkes \& Blakemore, 2018). Understanding 
qualitative (e.g. type) and quantitative (e.g. magnitude) differences in developmental experiences is critical to generating well-informed conceptualisations of development that are relevant to the contexts in which young people live.

A life-course perspective acknowledges developmental change in relation to social and structural determinants of health (Brook, Morojele, Zhang, \& Brook, 2006; Sawyer et al., 2012). The development of young people unfolds as a transactional process that is the product of bidirectional and synergistic effects of the individual and their experiences within the social environment (Sameroff, 2009). Capacity for adaptive functioning is distributed across interacting systems and reflects evolutionary shifts in biology and culture, with maladaptive patterns representing decreases in functioning within and across multiple systems (Masten, 2014). Importantly, maladjustment can be attributed to or exacerbated by factors at cultural and contextual levels (i.e. social-structural vulnerabilities) that extend beyond the individual (Ungar, 2011). Social-structural vulnerabilities (e.g. lack of education, poverty, gender inequality, discriminatory policies or legal frameworks) tend to heighten exposure of young people to dysfunctional systems, which can disrupt typical trajectories of development and create barriers to successfully navigating pathways of risk. While risky behaviours are a part of the normative dialogue around the development of young people, environments that lack protective processes at social and structural levels may predispose this population to a variety of health risks (e.g. substance abuse, violence), including HIV. In the sections that follow, we consider salient development and role transition processes of young people and contextualise these in relation to some of the social-structural vulnerabilities that exist in ESA.

\section{Developmental processes in contexts of social-structural vulnerability}

\section{Pubertal changes}

Puberty (mean age of onset is 12 years in males and 11 years in females) is associated with progressive development of sexual and reproductive organs and physical changes indicative of sexual maturity (Blakemore, Burnett, \& Dahl, 2010; Byrne et al., 2017). Although the pubertal development process is typical of all adolescents, there are individual differences in the timing and tempo of maturation (Beltz, Corley, Bricker, Wadsworth, \& Berenbaum, 2014).

Adolescents who physically mature earlier have been found to be at higher risk of psychological problems because of mismatches between physical growth and their developmental readiness for the biopsychosocial changes that occur (Ge, Brody, Conger, Simons, \& Murry, 2002; Ge et al., 2003). For girls, who generally enter puberty earlier than boys (Abreu \& 


\section{Richard G. Cowden et al.}

Kaiser, 2016), the risks of maladjustment are sometimes higher (Graber, 2013) because early maturing girls are more likely to stand out from their age-matched peers and affiliate with older peers (Mrug et al., 2014).

Marked economic and gender inequalities in ESA are involved in creating pressure among girls to engage in age-disparate relations or intergenerational sex (i.e. partnerships in which one partner is five or more years younger than the other partner) as a means of fulfilling needs (e.g. socioeconomic freedom and security) that extend beyond interpersonal intimacy and belonging (Mampane, 2018). Age-disparate relationships are sustained by the physical and emotional needs of young people, which are emerging in contexts of deprivation where youth are searching for a gateway to a middle-class lifestyle. The seemingly transactional nature of these relationships continues to activate debate about whether young women are exercising agency or being coerced into such relationships (Wamoyi et al., 2019). Notwithstanding potential rewards or immediate gratification, intergenerational sex has been associated with risky sexual practices and elevated risk of HIV infection (Leclerc-Madlala, 2008; Ritchwood et al., 2016).

High rates of gender-based violence against women within ESA is another social vulnerability that impedes the ability of young women to negotiate safe sex (MacPherson, Richards, Namakhoma, \& Theobald, 2014), as they may have concerns over the potential repercussions of not complying with their partner's sexual demands or expectations (O'Sullivan, Harrison, Morrell, Monroe-Wise, \& Kubeka, 2006). Gender inequality remains a broader sociocultural issue in many countries within ESA. Legislative policies often lack holistic frameworks to be able to offer sufficient protection and support to young women who experience sexual and gender-based violence (van Eerdewijk et al., 2018). Consequently, the challenges associated with navigating biopsychosocial changes that occur during adolescence may be amplified in high-risk environments where structural mechanisms to combat risk and promote well-being are underdeveloped.

\section{Neurological changes}

Adolescence is one of the most sensitive periods for brain development (Steinberg, 2014). During this developmental phase, neuronal networks throughout the brain are optimised and fine-tuned (Arain et al., 2013). Structural changes to the prefrontal cortex, in particular, are linked to important advances in executive functions (Anderson, 2002), including planning, decision-making, and regulation of thought and action (Casey, Jones, \& Hare, 2008). Over time, improvements in cognitive control lead to better decision-making processes and inhibition of impulsive behaviour (Blakemore \& Choudhury, 2006). Developments in frontal-parietal lobe circuitry contribute to increasingly sophisticated social-cognitive processes that promote interpersonal functioning, including advances 
in adolescents' proclivity to experience empathy and perspective-taking abilities (Blakemore \& Mills, 2014; Dumontheil, Apperly, \& Blakemore, 2010).

Key neurochemical processes have been linked to the relative immaturity of the prefrontal cortex during adolescence, including the gammaaminobutyric acid (GABA) and dopamine systems of neurotransmission (Arain et al., 2013). In the prefrontal cortex, delayed maturation of the GABA system, coupled with elevated levels of dopamine (Wahlstrom, Collins, White, \& Luciana, 2010), contribute to adolescents' appetite for novel experiences, exploratory behaviour, and sensation-seeking tendencies (Spear, 2000).

Although the likelihood of risk-taking behaviour increases as young people pursue novel and stimulating experiences (Blakemore et al., 2010), behavioural choices are also affected by the broader environmental context. In ESA, where the prevalence of infectious disease is high (Murray et al., 2012) and access to quality healthcare is limited (Fullman et al., 2018), young people are particularly vulnerable to health consequences associated with risky behaviours. For example, the age at which adolescents are able to independently access medical care varies across countries in ESA, including specific regulations on parental consent for HIV testing (Govender, Nyamaruze, Cowden, \& Armstrong, in press). Sometimes, the legal age of consenting to sex (typically 15 or 16 years of age) is lower than the age young people are legally permitted to access sexual and reproductive health services independent of their parents (typically when young people are granted legal status as adults at 18 years of age). Furthermore, social norms and legislative environments in ESA tend to be repressive against young key populations (e.g. those who selfidentify as part of the LGBTQ+ community). Many ESA countries maintain policies and legal frameworks that criminalise the identities and sexual activities of key populations (Govender et al., 2018). These kinds of sociopolitical discrepancies and barriers not only conflict with young people's progressive sense of autonomy and capacity to self-regulate, but they may also reduce health-seeking behaviours and obstruct access to HIV care and treatment services (Baggaley, Armstrong, Dodd, Ngok$\sin$, \& Krug, 2015).

\section{Psychological changes}

With maturation, adolescents' cognitive abilities shift away from concrete operational thought processes (Piaget, 1964) towards higher-order cognitive capabilities (e.g. hypothetical-deductive reasoning, abstract thought, improvements in speed of information processing) that enable young people to weigh risks into decision-making and exert better control over behavioural choices (Steinberg, 2005). Alongside acquisition of general higher-order cognitive abilities, adolescence is accompanied 
by developments in moral reasoning. Early perspectives (see Kohlberg \& Hersh, 1977) conceptualise moral judgement in young people as a progressive socialisation process towards the internalisation of universal moral principles. More recent models (see Rest Narvaez, Thoma, \& Bebeau, 2000) emphasise the role of contextually specific influences (e.g. common morality) on the development of moral judgement. Young people make value judgements around sexual practice that are usually dependent on social and structural factors such as poverty, family structure, educational background, gender inequality, and conceptions of romantic relationships. For example, women may fear violence in response to requesting condom use with their sexual partners. Heightened egocentrism (e.g. unrealistic, biased, and self-serving judgements) associated with dominant constructs of masculinity may also undermine adolescents' ability to make independent judgements. Studies have found that expectations of sexual behaviour among men that reflect hypermasculine norms, including sexual appetite, prowess, and conquest (Brown, Sorrell, \& Raffaelli, 2005; Shefer, Kruger, \& Schepers, 2015), are linked to HIV risk (Fleming, DiClemente, \& Barrington, 2016).

Similarly, macro-level environmental factors can influence identity formation processes that are central to development. Young people living in socially repressive contexts have more constraints on their agency to explore, expand, and diversify their social selves. Identity formation processes may be foreclosed or restricted by prevailing norms and policies. For example, many socially conservative countries in ESA have legislative restrictions (e.g. criminalisation of same-sex relations) that reinforce stigma and prejudice against members of key populations. Due to the constraints and prejudices that relevant regulations and policies impose on members of key populations, narrowly defined codes of conduct can have negative effects on the psychological adjustment (e.g. diminished sense of self-worth, feelings of social isolation) of members of young key populations as they transition to adulthood (Govender et al., in press). Young people may also be reluctant to seek sexual and reproductive healthcare services due to concerns about discrimination and potential legal ramifications that may be linked to the behaviours they participate in (Baggaley et al., 2015), which could ultimately lead to unfavourable health outcomes.

\section{Social changes}

During adolescence, young people expand their social landscapes beyond familial boundaries to extrafamilial attachment figures (e.g. peers, romantic relationships). They begin to spend more time in the company of their peers (Lam, McHale, \& Crouter, 2014) and ascribe greater value to peer opinions and expectations (van Hoorn, van Dijk, Meuwese, Rieffe, \& Crone, 2014). Peers serve as role models, provide age- and sex-appropriate standards of acceptable behaviour, and shape behaviour through interactions 
that reinforce or extinguish behaviour (Crosnoe \& McNeely, 2008; Smetana, 2010). Acquired norms may be incorporated into existing standards of behaviour and form part of an individual's subsequent behaviours and decision-making (Berger, 2008). Although the implications of peer influences are heterogenous and can facilitate healthy adjustment (van Hoorn et al., 2014), in vulnerable contexts there are greater risks and consequences of negative peer influences. Adolescents' need to belong and feel accepted may be exploited by peer pressure to conform to deviant or otherwise risky behaviours, particularly those involving substance use (e.g. tobacco, alcohol) and sexual activity (Govender, Cowden, Oppong Asante, George, \& Reardon, 2019). These kinds of health-risk behaviours often do not occur in isolation and can synergistically increase risk. For example, adolescents who consume alcohol are more likely to initiate sex at an earlier age and engage in risky sexual practices (e.g. multiple sexual partners) compared to alcohol abstaining peers (Morojele, Nkosi, Kekwaletswe, Saban, \& Parry, 2013).

There are also broader contextual dynamics that can affect adolescents' access to recreational substances and ease of engagement in health-risk behaviours. Recent evidence (see Gray-Phillip et al., 2018) indicates that alcohol is readily available for purchase among underage persons in countries within ESA (e.g. South Africa). General accessibility of recreational substances is mediated by environments that enable adolescents to participate in substance use. Studies have found that substance use on school premises tends to be higher when young people believe that repercussions of such activities are unlikely (Evans-Whipp, Plenty, Catalano, Herrenkohl, \& Toumbourou, 2013). When sociocontextual consequences of deviant behaviour are outweighed by the perceived benefits, anticipation of generally positive outcomes may affect the decisions of young people to engage in health-risk behaviour (Piontek et al., 2008).

By mid to late adolescence, many young people begin to form intimate romantic relationships (Tanti, Stukas, Halloran, \& Foddy, 2011). Dating relationships represent a novel and distinctive type of social engagement for adolescents, which are influenced by prior experiences in attachment relationships (e.g. parents, peers) and further shape a young person's identity, perspectives on relationships, and behaviour (Giordano, Manning, \& Longmore, 2006). Perceived pressure to conform to peer norms about romantic relationships influences when young people decide to begin dating relationships, who they enter into relationship with, and the norms they internalise about sexual intimacy within romantic relationships (van Zantvliet, Ivanova, \& Verbakel, 2020).

In ESA, social-structural features of the environment (e.g. poverty) are involved in motivating young people to pursue romantic relationships as a means of fulfilling material needs. Young women may engage in transactional sexual relationships to meet basic needs (e.g. food security), gain access to financial support and material gifts, and acquire social status (UNAIDS, 2018). Transactional characteristics of relationships reinforce 
traditional norms of hegemonic masculinity (e.g. male dominance) and can lead to tolerance of coercion and compliance with male demands about sexual practices (Wamoyi, Fenwick, Urassa, Zaba, \& Stones, 2011; Wamoyi et al., 2019). Masculine ideologies (e.g. virility) encourage and endorse risky sexual practices (e.g. multiple, concurrent sexual partners) among young men, which serve as signals of sexual prowess, control over women, and power over other men (Fleming et al., 2016). Together, these kinds of social-structural dynamics conjunctively contribute to fluid partnership patterns (e.g. casual partnering, frequent partner changes) that heighten young people's risk of contracting HIV (Bongaarts, 2007).

\section{Role transitions in contexts of social-structural vulnerability}

In contexts of social-structural vulnerability where disruptions in parental or caregiver attachment (e.g. orphanhood, parental absence) are pervasive (Newlin, Reynold, \& Nombutho, 2016), young people are at increased risk of prematurely assuming adult roles and responsibilities (e.g. heads of households) for which they are unprepared (Meintjes, Hall, Marera, \& Boulle, 2010; Mturi, 2012). Minors who assume positions as head of household are concentrated in ESA (Collins et al., 2016), and the burden of being responsible for the needs of other family members can be emotionally, psychologically, and physically taxing (see Boris et al., 2008; Hartell \& Chabilall, 2005; Satzinger, Kipp, \& Rubaale, 2012). Furthermore, the challenges of prematurely navigating adult responsibilities in vulnerable social contexts are often compounded by structural constraints that impact employment opportunities, food security, educational attainment, and access to supportive social programming (Collins et al., 2016; Mkhatshwa, 2017).

A similarly abrupt transition to adulthood occurs among young women who are involuntarily married as children. Early child marriages are prevalent in countries within ESA (Koski, Clark, \& Nandi, 2017) and may be motivated by intersecting cultural dynamics (e.g. symbolism of social status for men, parents' needs for young women to become 'productive') and the structural vulnerabilities (e.g. prospect of family inheriting bride wealth to alleviate poverty) that exist in the region (Schaffnit, Urassa, \& Lawson, 2019). Child marriages not only infringe on rights to self-determination and thwart personal growth opportunities for young women, but they are also linked to highly inequitable, exploitive relationships characterised by gender-based violence and unsafe sexual practices (Kidman, 2017; Raj, Jackson, \& Dunham, 2018).

Another prominent early role transition in ESA is motherhood at a young age, where rates of pregnancy and childbearing among adolescent girls remain persistently high (Yakubu \& Salisu, 2018). Although it is not uncommon for young women in ESA to have a child as a form of celebrating womanhood (Sennott \& Mojola, 2017), unplanned teenage pregnancies 
and childbirths are driven by broader social (e.g. unequal gender power dynamics, coercive sexual relations) and structural (e.g. poverty, unavailable or inaccessible educational opportunities, barriers to contraception) vulnerabilities in this region (Yakubu \& Salisu, 2018). Psychosocial consequences of unplanned and unmarried childbirth may include social stigma and family rejection, which can provoke unsafe abortions and exacerbate the challenges of navigating adult responsibilities of parenthood as an adolescent (see Izugbara, Ochako, \& Izugbara 2011; Levandowski et al., 2012). As young girls who bear children are more likely to permanently discontinue their educational pursuits (Wodon et al., 2017), teenage pregnancy and parenthood in vulnerable contexts may have long-term implications for maintaining or perpetuating intergenerational cycles of poverty and gender inequality (Swartz, Colvin, \& Harrison, 2018; Wood \& Hendricks, 2017).

Vertically infected HIV-positive young people who grow up in ESA are uniquely affected by compounded vulnerabilities as they transition to adulthood. Social stigmatisation may lead to discrimination, social disintegration, and barriers to appropriate support mechanisms (Boushab, Fall-Malick, Ould Cheikh Melainine, \& Basco, 2017). These consequences aggravate pre-existing psychological distress (e.g. low self-worth, self-stigmatisation, internalising symptoms) during a period when young people are increasingly interested in broadening their social landscapes and their need to belong and feel accepted intensifies (Bennett, Hersh, Herres, \& Foster, 2016). Interpersonal and self-imposed HIV-related stigma may reduce helpseeking behaviours and restrict access to healthcare services (Rueda et al., 2016), which are necessary for treating HIV effectively, receiving guidance on safe sexual practices, and obtaining professional support for mental health issues.

\section{Overcoming social-structural vulnerabilities: building resilience in context}

Even though structural challenges can create overwhelming obstacles that have the potential to interfere with development, young people living in contexts of social-structural vulnerability frequently emerge well-adjusted (Masten, 2014). Young people are able to adapt successfully in economically disadvantaged and high-risk social environments by drawing upon culturally embedded networks of functionally interrelated resources available to them (Ungar, 2011). Recent reviews of resilience research involving samples of children and youth from countries in ESA (e.g. Betancourt, Meyers-Ohki, Charrow, \& Hansen, 2013; van Breda \& Theron, 2018) have identified a range of protective processes (e.g. individual, family, community, cultural) that enable resilience, highlighting the diversity of internal and external resources that may be accessible to young people in this region. Mobilisation of community-level resources is a particularly useful 
means of developing health-enabling environments for overcoming socialstructural vulnerabilities (Thomas-Slayter \& Fisher, 2011). AIDS-competent communities create health-enabling environments for young people by encouraging engagement and providing avenues for participating in collective dialogue, collectively agreeing on a shared purpose and taking responsibility for the HIV epidemic, and being involved in educating people about HIV prevention and supporting access to healthcare needs (Campbell, Nair, Maimane, \& Gibbs, 2009).

Multilevel resilience-enabling resources may be shared among young people across contexts, yet there is heterogeneity in manifestations of resilience among different populations (Ungar, 2008). Interpretations of resilience in contexts of social-structural vulnerability ought to consider self-constructed definitions of successful adaptation among young people (Ungar, 2004). An inclusive perspective that recognises multiple pathways and manifestations of resilience is likely to improve our understanding of how unorthodox pathways may be involved in young people's achievement of non-standard expressions of resilience (Theron, 2016; Ungar, 2008), which can be integrated into the development of contextually relevant HIV prevention programmes for young people living in ESA.

\section{Conclusion}

This chapter offered an integrative overview of the contextualised biopsychosocial development of young people in ESA. Although biological change is an inevitable part of adolescent development, there remain maturational disparities and idiosyncratic differences in the way these changes occur. By opening boundaries of childhood and adulthood beyond the typical notion of chronological age, young people may be placed at different points along a developmental trajectory depending on their unique personal circumstances and the social contexts in which they live.

Acquisition of HIV cannot be explained simply at the level of individual behaviour and biology. Rather, HIV risk among young people needs to be interpreted in relation to the broader context of the epidemic. Contextual realities play a key role in how young people negotiate their identities, including their sexual and relational selves. It is important to consider the broader cultural milieu and immediate community influences on societal perceptions of young people and the way in which they perceive themselves. A more holistic view of sexuality may provide a gateway to understanding the role of sociocultural influences on decisions related to sexual activity. Comprehensive frameworks for conceptualising sexual risk behaviour are likely to encourage prevention efforts that take a contextualised, multifaceted approach to targeting risk factors at multiple levels of proximity to the individual. 


\section{Note}

1 Young people is an inclusive term (see World Health Organization, 2018) that captures phases of younger adolescence (10 to 14 years), older adolescence (15 to 19 years), and young adulthood (20 to 24 years).

\section{References}

Abreu, A.P., \& Kaiser, U.B. (2016). Pubertal development and regulation. Lancet Diabetes $\mathcal{E}$ Endocrinology, 4, 254-264. doi:10.1016/S2213-8587(15)00418-0

Anderson, P. (2002). Assessment and development of executive function (EF) during childhood. Child Neuropsychology, 8, 71-82. doi:10.1076/chin.8.2.71.8724

Arain, M., Haque, M., Johal, L., Mathur, P., Nel, W., Rais, A., . . Sharma, S. (2013). Maturation of the adolescent brain. Neuropsychiatric Disease and Treatment, 9, 449-461. doi:10.2147/NDT.S39776

Baggaley, R., Armstrong, A., Dodd, Z., Ngoksin, E., \& Krug, A. (2015). Young key populations and HIV: A special emphasis and consideration in the new WHO consolidated guidelines on HIV prevention, diagnosis, treatment and care for key populations. Journal of the International AIDS Society, 18(Suppl. 1), 19438. doi:10.7448/IAS.18.2.19438

Beltz, A. M., Corley, R. P., Bricker, J. B., Wadsworth, S.J., \& Berenbaum, S.A. (2014). Modeling pubertal timing and tempo and examining links to behavior problems. Developmental Psychology, 50, 2715-2726. doi:10.1037/a0038096

Bennett, D. S., Hersh, J., Herres, J., \& Foster, J. (2016). HIV-related stigma, shame, and avoidant coping: Risk factors for internalizing symptoms among youth living with HIV? Child Psychiatry E Human Development, 47, 657-664. doi:10.1007/ s10578-015-0599-y

Berger, J. (2008). Identity signaling, social influence, and social contagion. In M.J. Prinstein \& K. A. Dodge (Eds.), Understanding peer influence in children and adolescents (pp. 181-199). New York, NY: Guilford Press.

Betancourt, T.S., Meyers-Ohki, S.E., Charrow, A., \& Hansen, N. (2013). Annual research review: Mental health and resilience in HIV/AIDS-affected children A review of the literature and recommendations for future research. Journal of Child Psychology and Psychiatry, 54, 423-444. doi:10.1111/j.1469-7610.2012.02613.x

Blakemore, S.-J., Burnett, S., \& Dahl, R.E. (2010). The role of puberty in the developing adolescent brain. Human Brain Mapping, 31, 926-933. doi:10.1002/ hbm.21052

Blakemore, S.-J., \& Choudhury, S. (2006). Development of the adolescent brain: Implications for executive function and social cognition. Journal of Child Psychology and Psychiatry, 47, 296-312. doi:10.1111/j.1469-7610.2006.01611.x

Blakemore, S.-J., \& Mills, K. L. (2014). Is adolescence a sensitive period for sociocultural processing? Annual Review of Psychology, 65, 187-207. doi:10.1146/ annurev-psych-010213-115202

Bongaarts, J. (2007). Late marriage and the HIV epidemic in sub-Saharan Africa. Population Studies, 61, 73-83. doi:10.1080/00324720601048343

Boris, N.W., Brown, L.A., Thurman, T.R., Rice, J.C., Snider, L. M., Ntaganira, J., \& Nyirazinyoye, L. N. (2008). Depressive symptoms in youth heads of household in Rwanda: Correlates and implications for intervention. Archives of Pediatrics $\mathcal{E}^{\circ}$ Adolescent Medicine, 162, 836-843. doi:10.1001/archpedi.162.9.836 
Boushab, B. M., Fall-Malick, F.-Z., Ould Cheikh Melaïnine, M. L., \& Basco, L. K. (2017). Forms of stigma and discrimination in the daily lives of HIV-positive individuals in Mauritania. Open AIDS Journal, 11, 12-17. doi:10.2174/1874613601711010012

Brook, D. W., Morojele, N.K., Zhang, C., \& Brook, J.S. (2006). South African adolescents: Pathways to risky sexual behaviour. AIDS Education and Prevention, 18, 259-272. doi:10.1521/aeap.2006.18.3.259

Brown, J., Sorrell, J., \& Raffaelli, M. (2005). An exploratory study of constructions of masculinity, sexuality and HIV/AIDS in Namibia, Southern Africa. Culture, Health E Sexuality, 7, 585-598. doi:10.1080/13691050500250198

Burman, E. (2008). Deconstructing developmental psychology (2nd ed.). New York, NY: Routledge.

Byrne, M.L., Whittle, S., Vijayakumar, N., Dennison, M., Simmons, J.G., \& Allen, N.B. (2017). A systematic review of adrenarche as a sensitive period in neurobiological development and mental health. Developmental Cognitive Neuroscience, 25, 12-28. doi:10.1016/j.dcn.2016.12.004

Campbell, C., Nair, Y., Maimane, S., \& Gibbs, A. (2009). Strengthening community responses to AIDS: Possibilities and challenges. In P. Rohleder, L. Swartz, \& S. Kalichman (Eds.), HIV/AIDS in South Africa 25 years on (pp. 221-235). London, UK: Springer.

Casey, B.J., Jones, R. M., \& Hare, T.A. (2008). The adolescent brain. Annals of the New York Academy of Sciences, 1124, 111-126. doi:10.1196/annals.1440.010

Collins, L., Ellis, M., Pritchard, E. W. J., Jenkins, C., Hoeritzauer, I., Farquhar, A., ... Nelson, B. D. (2016). Child-headed households in Rakai District, Uganda: A mixed-methods study. Paediatrics and International Child Health, 36, 58-63. doi:10.1179/2046905514Y.0000000152

Crosnoe, R., \& McNeely, C. (2008). Peer relations, adolescent behavior, and public health research and practice. Family $\mathcal{E}^{\circ}$ Community Health, 31(Suppl. 1), S71-S80. doi:10.1097/01.FCH.0000304020.05632.e8

Dumontheil, I., Apperly, I.A., \& Blakemore, S.-J. (2010). Online usage of theory of mind continues to develop in late adolescence. Developmental Science, 13, 331-338. doi:10.1111/j.1467-7687.2009.00888.x

Evans-Whipp, T.J., Plenty, S. M., Catalano, R.F., Herrenkohl, T. I., \& Toumbourou, J.W. (2013). The impact of school alcohol policy on student drinking. Health Education Research, 28, 651-662. doi:10.1093/her/cyt068

Fleming, P.J., DiClemente, R.J., \& Barrington, C. (2016). Masculinity and HIV: Dimensions of masculine norms that contribute to men's HIV-related sexual behaviors. AIDS and Behavior, 20, 788-798. doi:10.1007/s10461-015-1264-y

Foulkes, L., \& Blakemore, S.-J. (2018). Studying individual differences in human adolescent brain development. Nature Neuroscience, 21, 315-323. doi:10.1038/ s41593-018-0078-4

Fullman, N., Yearwood, J., Abay, S. M., Abbafati, C., Abd-Allah, F., Abdela, J., . . . Lozano, R. (2018). Measuring performance on the Healthcare Access and Quality Index for 195 countries and territories and selected subnational locations: A systematic analysis from the Global Burden of Disease Study 2016. Lancet, 391, 2236-2271. doi:10.1016/S0140-6736(18)30994-2

Ge, X., Brody, G.H., Conger, R. D., Simons, R. L., \& Murry, V. M. (2002). Contextual amplification of pubertal transition effects on deviant peer affiliation and externalizing behavior among African American children. Developmental Psychology, 38, 42-54. doi:10.1037/0012-1649.38.1.42 
Ge, X., Kim, I.J., Brody, G.H., Conger, R.D., Simons, R. L., Gibbons, F. X., \& Cutrona, C.E. (2003). It's about timing and change: Pubertal transition effects on symptoms of major depression among African American youths. Developmental Psychology, 39, 430-439. doi:10.1037/0012-1649.39.3.430

Giordano, P.C., Manning, W.D., \& Longmore, M.A. (2006). Adolescent romantic relationships: An emerging portrait of their nature and developmental significance. In A.C. Crouter \& A. Booth (Eds.), Romance and sex in adolescence and emerging adulthood: Risks and opportunities (pp. 127-150). Mahwah, NJ: Lawrence Erlbaum Associates.

Govender, K., Cowden, R.G., Oppong Asante, K., George, G., \& Reardon, C. (2019). Sexual risk behavior: A multi-system model of risk and protective factors in South African adolescents. Prevention Science, 20, 1054-1065. doi:10.1007/ s11121-019-01015-3

Govender, K., Masebo, W., Nyamaruze, P., Cowden, R. G., Schunter, B., \& Bains, A. (2018). HIV prevention in adolescents and young people in the Eastern and Southern African region: A review of key challenges impeding actions for an effective response. Open AIDS Journal, 12, 53-67. doi:10.2174/18746136018120 10038

Govender, K., Nyamaruze, P., Cowden, R. G., \& Armstrong, R. (in press). Legal, policy and social barriers to accessing HIV and sexual and reproductive health services among young key populations in Eastern and Southern Africa. Johannesburg, South Africa: Eastern and Southern Africa Regional Inter-Agency Task Team on Children Affected by AIDS.

Graber, J.A. (2013). Pubertal timing and the development of psychopathology in adolescence and beyond. Hormones and Behavior, 64, 262-269. doi:10.1016/j. yhbeh.2013.04.003

Gray-Phillip, G., Huckle, T., Callinan, S., Parry, C. D. H., Chaiyasong, S., Cuong, P.V., . . Casswell, S. (2018). Availability of alcohol: Location, time and ease of purchase in high- and middle-income countries: Data from the international alcohol control study. Drug and Alcohol Review, 37(Suppl. 2), S36-S44. doi:10.1111/ dar.12693

Hartell, C. G., \& Chabilall, J.A. (2005). HIV/AIDS in South Africa: A study of the socio-educational development of adolescents orphaned by AIDS in child-headed households. International Journal of Adolescence and Youth, 12, 213-229. doi:10.1080/ 02673843.2005 .9747953

Hogan, D. (2005). Researching "the child" in developmental psychology. In S. Greene \& D. Hogan (Eds.), Researching children's experience: Approaches and methods (pp. 22-41). London, UK: Sage.

Izugbara, C. O., Ochako, R., \& Izugbara, C. (2011). Gender scripts and unwanted pregnancyamong urban Kenyan women. Culture, Health ES Sexuality, 13, 1031-1045. doi:10.1080/13691058.2011.598947

Kidman, R. (2017). Child marriage and intimate partner violence: A comparative study of 34 countries. International Journal of Epidemiology, 46, 662-675. doi:10.1093/ije/dyw225

Kohlberg, L., \& Hersh, R.H. (1977). Moral development: A review of the theory. Theory Into Practice, 16, 53-59. doi:10.1080/00405847709542675

Koski, A., Clark, S., \& Nandi, A. (2017). Has child marriage declined in sub-Saharan Africa? An analysis of trends in 31 countries. Population and Development Review, 43, 7-29. doi:10.1111/padr.12035 


\section{Richard G. Cowden et al.}

Lam, C.B., McHale, S. M., \& Crouter, A.C. (2014). Time with peers from middle childhood to late adolescence: Developmental course and adjustment correlates. Child Development, 85, 1677-1693. doi:10.1111/cdev.12235

Leclerc-Madlala, S. (2008). Age-disparate and inter-generational sex in Southern Africa: The dynamics of hypervulnerability. AIDS, 22(Suppl. 4), S17-S25. doi:10.1097/01.aids.0000341774.86500.53

Levandowski, B. A., Kalilani-Phiri, L., Kachale, F., Awah, P., Kangaude, G., \& Mhango, C. (2012). Investigating social consequences of unwanted pregnancy and unsafe abortion in Malawi: The role of stigma. International Journal of Gynecology E Obstetrics, 118(Suppl. 2), S167-S171. doi:10.1016/S0020-7292(12)60017-4

Linders, A. (2017). Deconstructing adolescence. In A. L. Cherry, V. Baltag, \& M.E. Dillon (Eds.), International handbook on adolescent health and development: The public health response (pp. 15-28). Cham, Switzerland: Springer.

MacPherson, E.E., Richards, E., Namakhoma, I., \& Theobald, S. (2014). Gender equity and sexual and reproductive health in Eastern and Southern Africa: A critical overview of the literature. Global Health Action, 7, 23717. doi:10.3402/gha. v7.23717

Mampane, J.N. (2018). Exploring the "blesser and blessee" phenomenon: Young women, transactional sex, and HIV in rural South Africa. SAGE Open, 8, 1-9. doi:10.1177/2158244018806343

Masten, A.S. (2014). Global perspectives on resilience in children and youth. Child Development, 85, 6-20. doi:10.1111/cdev.12205

Meintjes, H., Hall, K., Marera, D.-H., \& Boulle, A. (2010). Orphans of the AIDS epidemic? The extent, nature and circumstances of child-headed households in South Africa. AIDS Care, 22, 40-49. doi:10.1080/09540120903033029

Mkhatshwa, N. (2017). The gendered experiences of children in child-headed households in Swaziland. African Journal of AIDS Research, 16, 365-372. doi:10.29 89/16085906.2017.1389756

Morojele, N. K., Nkosi, S., Kekwaletswe, C.T., Saban, A., \& Parry, C. D. H. (2013). Review of research on alcohol and HIV in sub-Saharan Africa. Tygerberg, South Africa: South African Medical Research Council. Retrieved from https://www.samrc. ac.za/sites/default/files/attachments/2016-06-27/AlcoholSubSaharan.pdf

Mrug, S., Elliott, M.N., Davies, S., Tortolero, S. R., Cuccaro, P., \& Schuster, M.A. (2014). Early puberty, negative peer influence, and problem behaviors in adolescent girls. Pediatrics, 133, 7-14. doi:10.1542/peds.2013-0628

Mturi, A.J. (2012). Child-headed households in South Africa: What we know and what we don't. Development Southern Africa, 29, 506-516. doi:10.1080/03768 35X.2012.706043

Murray, C. J. L., Vos, T., Lozano, R., Naghavi, M., Flaxman, A. D., Michaud, C., . . . Lopez, A.D. (2012). Disability-adjusted life years (DALYs) for 291 diseases and injuries in 21 regions, 1990-2010: A systematic analysis for the Global Burden of Disease Study 2010. Lancet, 380, 2197-2223. doi:10.1016/S0140-6736(12)61689-4

Newlin, M., Reynold, S., \& Nombutho, M. (2016). Children from child-headed households: Understanding challenges that affect in their academic pursuits. Journal of Human Ecology, 54, 158-173. doi:10.1080/09709274.2016.11906998

O'Sullivan, L.F., Harrison, A., Morrell, R., Monroe-Wise, A., \& Kubeka, M. (2006). Gender dynamics in the primary sexual relationships of young rural South African women and men. Culture, Health $\mathcal{E}$ Sexuality, 8, 99-113. doi:10.1080/13691050600665048 
Piaget, J. (1964). Part I: Cognitive development in children: Piaget development and learning. Journal of Research in Science Teaching, 2, 176-186. doi:10.1002/ tea.3660020306

Piontek, D., Buehler, A., Rudolph, U., Metz, K., Kroeger, C., Gradl, S., . . Donath, C. (2008). Social contexts in adolescent smoking: Does school policy matter? Health Education Research, 23, 1029-1038. doi:10.1093/her/cym063

Raj, A., Jackson, E., \& Dunham, S. (2018). Girl child marriage: A persistent global women's health and human rights violation. In S. Choudhury, J. T. Erausquin, \& M. Withers (Eds.), Global perspectives on women's sexual and reproductive health across the lifecourse (pp. 3-19). Cham, Switzerland: Springer.

Rest, J.R., Narvaez, D., Thoma, S.J., Bebeau, M.J. (2000). A neo-Kohlbergian approach to morality research. Journal of Moral Education, 29, 381-395. doi:10.1080/ 03057240020015001

Ritchwood, T.D., Hughes, J.P., Jennings, L., MacPhail, C., Williamson, B., Selin, A., ... Pettifor, A. (2016). Characteristics of age-discordant partnerships associated with HIV risk among young South African women (HPTN 068). Journal of Acquired Immune Deficiency Syndromes, 72, 423-429. doi:10.1097/QAI.0000000000000988

Rueda, S., Mitra, S., Chen, S., Gogolishvili, D., Globerman, J., Chambers, L., . . . Rourke, S. B. (2016). Examining the associations between HIV-related stigma and health outcomes in people living with HIV/AIDS: A series of meta-analyses. BMJ Open, 6, e011453. doi:10.1136/bmjopen-2016-011453

Sameroff, A. (2009). The transactional model. In A. Sameroff (Ed.), The transactional model of development: How children and contexts shape each other (pp. 3-21). Washington, DC: American Psychological Association.

Satzinger, F., Kipp, W., \& Rubaale, T. (2012). Ugandan HIV/AIDS orphans in charge of their households speak out: A study of their health-related worries. Global Public Health, 7, 420-431. doi:10.1080/17441690903339652

Sawyer, S. M., Afifi, R.A., Bearinger, L.H., Blakemore, S.-J., Dick, B., Ezeh, A.C., \& Patton, G. C. (2012). Adolescence: A foundation for future health. Lancet, 379, 1630-1640. doi:10.1016/S0140-6736(12)60072-5

Schaffnit, S. B., Urassa, M., \& Lawson, D.W. (2019). "Child marriage" in context: Exploring local attitudes towards early marriage in rural Tanzania. Sexual and Reproductive Health Matters, 27, 1571304. doi:10.1080/09688080.2019.1571304

Sennott, C., \& Mojola, S.A. (2017). 'Behaving well': The transition to respectable womanhood in rural South Africa. Culture, Health $\mathcal{E}$ Sexuality, 19, 781-795. doi:10.1080/13691058.2016.1262062

Shefer, T., Kruger, L.-M., \& Schepers, Y. (2015). Masculinity, sexuality and vulnerability in 'working' with young men in South African contexts: 'You feel like a fool and an idiot ... a loser'. Culture, Health E Sexuality, 17(Suppl. 2), S96-S111. doi: 10.1080/13691058.2015.1075253

Smetana, J.G. (2010). Adolescents, families, and social development: How teens construct their worlds. Chichester, UK: John Wiley \& Sons.

Spear, L.P. (2000). The adolescent brain and age-related behavioral manifestations. Neuroscience E Biobehavioral Reviews, 24, 417-463. doi:10.1016/S01497634(00) 00014-2

Steinberg, L. (2005). Cognitive and affective development in adolescence. Trends in Cognitive Sciences, 9, 69-74. doi:10.1016/j.tics.2004.12.005

Steinberg, L. (2014). Age of opportunity: Lessons from the new science of adolescence. New York, NY: Houghton Mifflin Harcourt. 
Swartz, A., Colvin, C., \& Harrison, A. (2018). The problem or the solution? Early fertility and parenthood in the transition to adulthood in Khayelitsha, South Africa. Reproductive Health Matters, 26, 145-154. doi:10.1080/09688080.2018.1537417

Tanti, C., Stukas, A.A., Halloran, M.J., \& Foddy, M. (2011). Social identity change: Shifts in social identity during adolescence. Journal of Adolescence, 34, 555-567. doi:10.1016/j.adolescence.2010.05.012

Theron, L.C. (2016). Toward a culturally and contextually sensitive understanding of resilience: Privileging the voices of black, South African young people. Journal of Adolescent Research, 31, 635-670. doi:10.1177/0743558415600072

Thomas-Slayter, B. P., \& Fisher, W.F. (2011). Social capital and AIDS-resilient communities: Strengthening the AIDS response. Global Public Health, 6(Suppl. 3), S323-S343. doi:10.1080/17441692.2011.617380

UNAIDS. (2017a). Ending AIDS: Progress towards the 90-90-90 targets. Geneva, Switzerland: UNAIDS. Retrieved from https://www.unaids.org/sites/default/files/ media_asset/Global_AIDS_update_2017_en.pdf

UNAIDS. (2017b). UNAIDS data 2017. Geneva, Switzerland: UNAIDS. Retrieved from https://www.unaids.org/sites/default/files/media_asset/20170720_Data_ book_2017_en.pdf

UNAIDS. (2018). Transactional sex and HIV risk: From analysis to action. Geneva, Switzerland: Joint United Nations Programme on HIV/AIDS and STRIVE. Retrieved from https://www.unaids.org/sites/default/files/media_asset/transac tional-sex-and-hiv-risk_en.pdf

Ungar, M. (2004). A constructionist discourse on resilience: Multiple contexts, multiple realities among at-risk children and youth. Youth $\mathcal{E}$ Society, 35, 341-365. doi:10.1177/0044118X03257030

Ungar, M. (2008). Putting resilience theory into action: Five principles for intervention. In L. Liebenberg \& M. Ungar (Eds.), Resilience in action (pp. 17-38). Toronto, Canada: University of Toronto Press.

Ungar, M. (2011). The social ecology of resilience: Addressing contextual and cultural ambiguity of a nascent construct. American Journal of Orthopsychiatry, 81, 1-17. doi:10.1111/j.1939-0025.2010.01067.x

van Breda, A.D., \& Theron, L.C. (2018). A critical review of South African child and youth resilience studies, 2009-2017. Children and Youth Services Review, 91, 237-247. doi:10.1016/j.childyouth.2018.06.022

van Eerdewijk, A., Kamunyu, M., Nyirinkindi, L., Sow, R., Visser, M., \& Lodenstein, E. (2018). The state of African women. Nairobi, Kenya: International Planned Parenthood Federation Africa Region. Retrieved from https:/ /www.ippfar.org/sites/ ippfar/files/2018-09/SOAW-Report-FULL\%20VERSION.pdf

van Hoorn, J., van Dijk, E., Meuwese, R., Rieffe, C., \& Crone, E. A. (2014). Peer influence on prosocial behavior in adolescence. Journal of Research on Adolescence, 26, 90-100. doi:10.1111/jora.12173

van Zantvliet, P. I., Ivanova, K., \& Verbakel, E. (2020). Adolescents' involvement in romantic relationships and problem behavior: The moderating effect of peer norms. Youth E' Society, 52, 574-591. doi:10.1177/0044118X17753643

Wahlstrom, D., Collins, P., White, T., \& Luciana, M. (2010). Developmental changes in dopamine neurotransmission in adolescence: Behavioral implications and issues in assessment. Brain and Cognition, 72, 146-159. doi:10.1016/j.bandc. 2009.10.013 
Wamoyi, J., Fenwick, A., Urassa, M., Zaba, B., \& Stones, W. (2011). "Women's bodies are shops": Beliefs about transactional sex and implications for understanding gender power and HIV prevention in Tanzania. Archives of Sexual Behavior, 40, 5-15. doi:10.1007/s10508-010-9646-8

Wamoyi, J., Heise, L., Meiksin, R., Kyegombe, N., Nyato, D., \& Buller, A. M. (2019). Is transactional sex exploitative? A social norms perspective, with implications for interventions with adolescent girls and young women in Tanzania. PLoS One, 14, e0214366. doi:10.1371/journal.pone.0214366

Wodon, Q., Male, C., Nayihouba, A., Onagoruwa, A., Savadogo, A., Yedan, A., . . . Petroni, S. (2017). Economic impacts of child marriage: Global synthesis brief. Washington, DC: The World Bank and International Center for Research on Women.

Wood, L., \& Hendricks, F. (2017). A participatory action research approach to developing youth-friendly strategies for the prevention of teenage pregnancy. Educational Action Research, 25, 103-118. doi:10.1080/09650792.2016.1169198

World Health Organization. (2018). Guidance on ethical considerations in planning and reviewing research studies on sexual and reproductive health in adolescents. Geneva, Switzerland: World Health Organization. Retrieved from https://apps.who.int/iris/ bitstream/handle/10665/273792/9789241508414-eng.pdf?ua=1

Yakubu, I., \& Salisu, W.J. (2018). Determinants of adolescent pregnancy in subSaharan Africa: A systematic review. Reproductive Health, 15, 15. doi:10.1186/ s12978-018-0460-4 